\title{
Long-term individual identification and site fidelity of white sharks, Carcharodon carcharias, off California using dorsal fins
}

\author{
Scot D. Anderson • Taylor K. Chapple • \\ Salvador J. Jorgensen • A. Peter Klimley • \\ Barbara A. Block
}

Received: 14 April 2010 / Accepted: 8 February 2011 / Published online: 1 March 2011

(C) The Author(s) 2011. This article is published with open access at Springerlink.com

\begin{abstract}
Mark-recapture techniques can be used to estimate white shark (Carcharodon carcharias) population abundance. These frameworks are based on assumptions that marks are conserved and animals are present at the sampling location over the entire duration of the study. Though these assumptions have been validated across short-time
\end{abstract}

Communicated by S. Garthe.

Electronic supplementary material The online version of this article (doi:10.1007/s00227-011-1643-5) contains supplementary material, which is available to authorized users.

\section{S. D. Anderson}

P.O. Box 390, Inverness, CA 94937, USA

e-mail: sharkman1137@mac.com

T. K. Chapple $(\varangle) \cdot$ A. P. Klimley

Wildlife, Fish and Conservation Biology,

University of California Davis, One Shields Ave,

Davis, CA 95616, USA

e-mail: tkchapple@ucdavis.edu

A. P. Klimley

e-mail: apklimley@ucdavis.edu

T. K. Chapple

Max Planck Institute for Ornithology,

Schlossallee 1a, 78315 Radolfzell, Germany

S. J. Jorgensen · B. A. Block

Hopkins Marine Station of Stanford University,

120 Oceanview Blvd., Pacific Grove, CA 93950, USA

e-mail: salvo@stanford.edu

B. A. Block

e-mail: bblock@stanford.edu

\section{S. J. Jorgensen}

Monterey Bay Aquarium, 886 Cannery Row,

Monterey, CA 93940, USA scales for white sharks, long-term studies of population trends are dependent on these assumptions being valid across longer periods. We use 22 years of photographic data from aggregation sites in central California to support the use of dorsal fin morphology as long-term individual identifiers. We identified five individuals over 16-22 years, which support the use of dorsal fins as long-time individual identifiers, illustrate strong yearly site fidelity to coastal aggregation sites across extended time periods (decades), and provide the first empirical validation of white shark longevity $>22$ years. These findings support the use of fin morphology in mark-recapture frameworks for white sharks.

\section{Introduction}

White sharks, Carcharodon carcharias, observed off the coast of California belong to a genetically distinct population unique to the eastern Pacific (Jorgensen et al. 2010). Subadult and adults travel long distances offshore from California and Northern Mexico during yearly migrations (Boustany et al. 2002; Weng et al. 2007; Domeier and Nasby-Lucas 2008; Jorgensen et al. 2010). These offshore movements traverse international waters where individuals are susceptible to fishing mortality, yet few data are available from potential offshore fisheries, confounding efforts to determine white shark population status. Therefore, fishery-independent methods must be employed to begin to estimate their population sizse.

Mark-recapture methods have been used to estimate white shark population sizes in South Africa (Cliff et al. 1996), Australia (Strong et al. 1996) and the northeast Pacific (Chapple et al. 2011). These studies are dependent on the assumption that white sharks return to the same location over multiple sampling periods. Recent work has illustrated the short-term [e.g., $<8$ years or $25 \%$ of estimated lifespan 
(Cailliet et al. 1985)] seasonal site fidelity of sharks to coastal aggregation sites. White sharks tagged off coastal California and Guadalupe Island, Mexico returned to their tagging location following offshore movements (Domeier and NasbyLucas 2008; Jorgensen et al. 2010). Similarly, a combination of a satellite tag and dorsal fin identification described the movement of a shark in South Africa to Australia and back in 9 months (Bonfil et al. 2005). However, no studies have tested the long-term [e.g., >14 years or $50 \%$ estimated lifespan (Cailliet et al. 1985)] site fidelity of these animals.

These mark-recapture frameworks also assume external identification tags or unique markings are conserved and identifiable throughout the study. Shedding and difficulty in application often confound the use of external tagging for identification. Therefore, current research on white sharks has focused on the use of distinctive natural markings as individual identifiers (Klimley and Anderson 1996; Strong et al. 1996; Bonfil et al. 2005; Domeier and Nasby-Lucas 2007; Gubili et al. 2009). One method proposed for individual identification in white sharks at Guadalupe Island utilizes pigmentation patterns (Domeier and Nasby-Lucas 2007). Though resighting requires only one photograph of the gill flaps, pelvic fin or caudal fin on either side, initial identification requires photographs of all three of these locations on both sides of the animal. In addition, the conditions necessary to support this type of identification, superb water visibility and high recreational diving effort, are unique to only Guadalupe Island. Collecting these data is likely to be too labor intensive and impractical in areas outside of Guadalupe Island with low water visibility (e.g., South Africa) and/or limited diving effort (e.g., California). Additionally, pigmentation patterns in several sharks were shown to naturally change in shape and/or size from year to year (Domeier and Nasby-Lucas 2007). Alternately, dorsal fins can be photographed from either side and are often observed out of the water, precluding issues with water clarity or the need for divers. Dorsal fin identification, requiring limited effort, is possible at all white shark aggregation sites globally. A comparison of matched individuals using genetic markers and dorsal fin photographs showed a high degree of concordance $(85 \%)$ between the two techniques over short (5 year) time periods (Gubili et al. 2009). This indicates that these patterns are unique enough to distinguish individuals. However, the stability of these marks over extended time periods remains unknown.

White sharks have been shown to exhibit short-term site fidelity and repeatable individual identification through dorsal fin photographs (Klimley and Anderson 1996; Strong et al. 1996; Anderson et al. 1996; Bonfil et al. 2005; Gubili et al. 2009) and body pigmentation (Klimley and Anderson 1996; Domeier and Nasby-Lucas 2007); however, in order to understand the long-term status of white sharks, mark-recapture studies must be expanded out to longer time series. Therefore, it is imperative to determine whether assumptions regarding site fidelity and identification are valid across these longer time periods (e.g., >14 years). Here, we aimed to determine (1) the stability of posterior edge dorsal fin morphology as individual identifiers over long time periods and (2) use this information to illustrate the long-term site fidelity of individual mature and subadult white sharks at coastal aggregation sites.

\section{Materials and methods}

This study began at the South Farallon Islands in 1987 (see Anderson et al. 1996). In 1998, the study was expanded to include coastal areas near Tomales Bay, California and beginning in 2005, a small amount of marine mammal blubber was used as bait to increase encounter rates and duration. High-resolution photographs and video were taken of each shark when they came near the surface to investigate a sealshaped decoy. We extracted dorsal fin images from these photographs and, if above water photographs were not available and water clarity permitted, from underwater video. Estimates of total length (TL) were also made when possible as sharks swam alongside a research skiff of known length.

Images were assessed for quality based on four criteria: angle, size, focus, and contrast. Images of insufficient quality were removed (see Online Resources 1 for discussion of photograph processing methods). Experts (individuals with demonstrated expertise matching dorsal fin photographs) then matched the remaining accepted fin photographs within and across all years simultaneously. If individuals were identified multiple times over the study period, we compared the earliest and latest photographs to determine long-term stability of dorsal fin morphology.

When possible, secondary characteristics (e.g., tags, permanent scars, mutilations, etc.) were used to validate these matches. In addition, we determined error rates of false identification using experimental matching trials. Experts matched 20 randomly chosen photographs from 12 sharks, which had obvious secondary characteristics (not evident in the fin photographs). Matching results from each expert were compared to the true matches based on these known secondary characteristics.

\section{Results}

We recorded 364 photographs of individual dorsal fins between 1987 and 2008. Confirmed males were sighted nearly twice as often as confirmed females (1.8:1), though this ratio may be biased because it is easier to confirm the presence of claspers than the absence. If the sex could not be confirmed, the animal was labeled "unknown." The ratio of known to unknown was 4.26:1. 


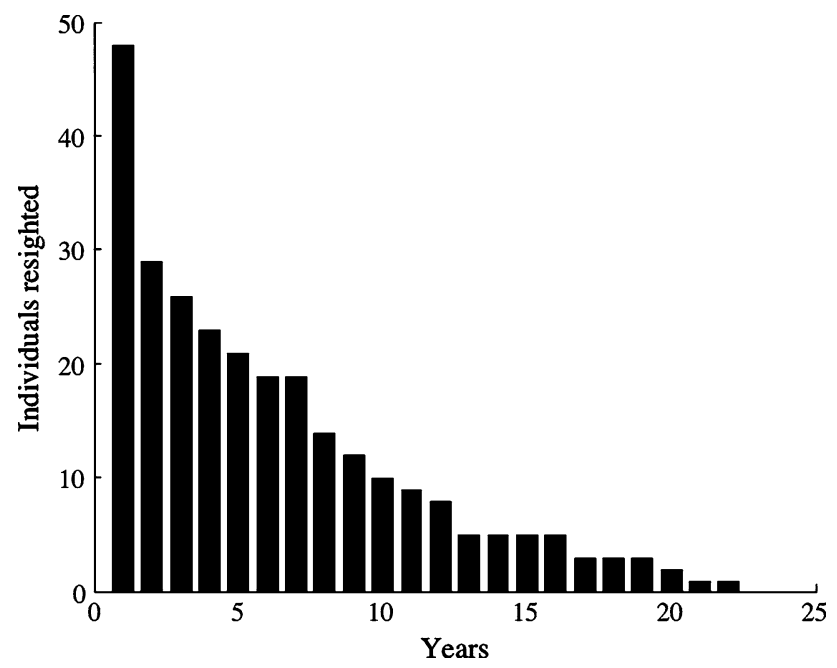

Fig. 1 Cumulative number of individuals identified repeatedly over time periods ranging from one to twenty-two years

Four experts accurately identified individuals and matches $98 \%$ of the time with no false positives and only one false negative. Similarly, Gubili et al. (2009) used genetic data to show nearly $85 \%$ accuracy in experts matching dorsal fin photographs.

Annually, limited effort and photograph quality resulted in the identification of few sharks before 2006 when effort increased and digital SLRs were used. Prior to 2006, over $60 \%$ of sharks were resighted (29 of 48). In 2006 and 2007, significantly more new sharks were recorded (76), but by $2008,35 \%$ (27) of these new sharks had been resighted at least once. Twenty-one individuals were repeatedly identified over periods $\geq 5$ year, ten individuals $\geq 10$ years, and five individuals $\geq 15$ years (Fig. 1). To illustrate the stability of markers and the empirical evidence of longevity, we describe five individuals resighted over periods $\geq 15$ years at South Farallon Islands (Fig. 2; Table 1).

The longest record was shark TJ, a 4.5-m-TL male. TJ was sighted 8 times over 22 years, initially in 1987 and most recently in 2008 (Fig 2a). Shark CT, a 3.5-m-TL male was sighted on 14 occasions over 20 years (Fig. 2b). FT, a 4-m-TL male, was sighted 7 times in 19 years (Fig. 2c). BH and RF, a 4-m-TL male sighted 9 times (Fig. 2d) and a 4m-TL male sighted four times (Fig. 2e), respectively, were identified over 16 years. All TL estimates given refer to the size at the most recent sighting of each shark.

\section{Discussion}

Our findings support the use of the trailing edge of the dorsal fin for long-term photo-identification studies at coastal aggregation sites. We photographically identified five white sharks repeatedly over a period of 16-22 years. Through
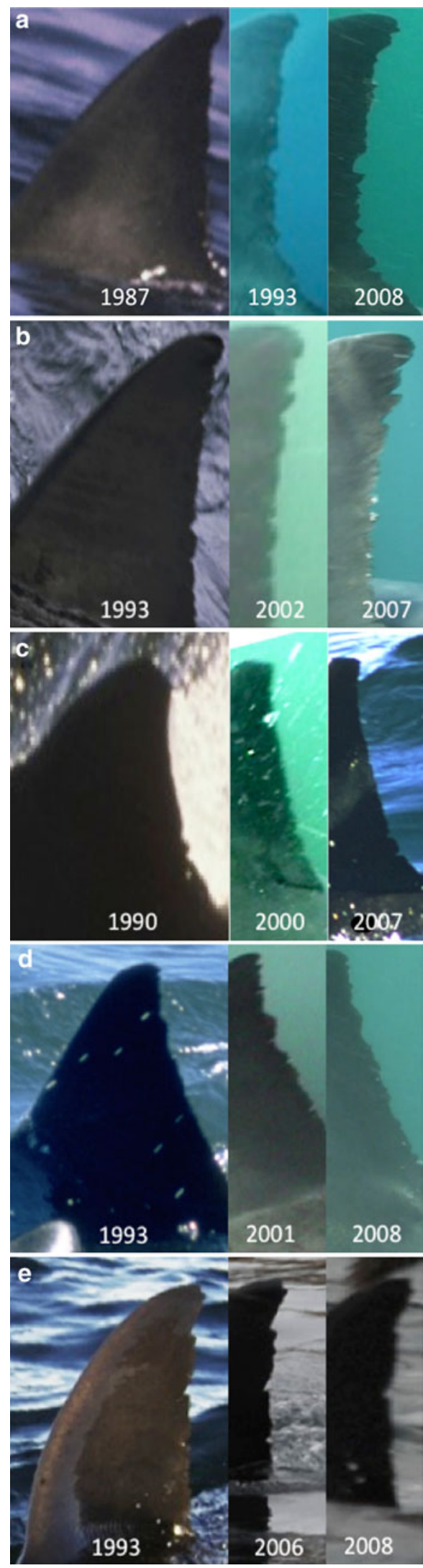

Fig. 2 Individuals a TJ, b CT, c FT, d BH, and e RF repeatedly identified by dorsal fin morphology over periods $>15$ years. The year indicates the date the photograph was taken 
Table 1 Yearly identification of five white sharks resighted between 1987 and 2008

\begin{tabular}{llllllllllllllllllllllllllllll}
\hline & 1987 & 1988 & 1989 & 1990 & 1991 & 1992 & 1993 & 1994 & 1995 & 1996 & 1997 & 1998 & 1999 & 2000 & 2001 & 2002 & 2003 & 2004 & 2005 & 2006 & 2007 & 2008 \\
\hline $\mathrm{BH}-$ & - & - & - & - & - & $\mathrm{X}$ & $\mathrm{X}$ & $\mathrm{X}$ & $\mathrm{X}$ & - & - & $\mathrm{X}$ & - & $\mathrm{X}$ & $\mathrm{X}$ & - & - & - & - & $\mathrm{X}$ & $\mathrm{X}$ \\
$\mathrm{CT}-$ & $\mathrm{X}$ & - & $\mathrm{X}$ & - & $\mathrm{X}$ & $\mathrm{X}$ & $\mathrm{X}$ & - & $\mathrm{X}$ & - & $\mathrm{X}$ & $\mathrm{X}$ & $\mathrm{X}$ & $\mathrm{X}$ & $\mathrm{X}$ & $\mathrm{X}$ & - & - & $\mathrm{X}$ & $\mathrm{X}$ & - \\
$\mathrm{FT}-$ & - & - & $\mathrm{X}$ & - & $\mathrm{X}$ & $\mathrm{X}$ & - & - & - & - & - & - & $\mathrm{X}$ & $\mathrm{X}$ & - & - & - & - & - & $\mathrm{X}$ & $\mathrm{X}$ \\
$\mathrm{RF}-$ & - & - & - & - & - & $\mathrm{X}$ & - & - & $\mathrm{X}$ & - & - & - & - & - & - & - & - & - & $\mathrm{X}$ & - & $\mathrm{X}$ \\
$\mathrm{TJ} \mathrm{X}$ & - & - & - & $\mathrm{X}$ & - & $\mathrm{X}$ & - & - & $\mathrm{X}$ & - & - & - & $\mathrm{X}$ & $\mathrm{X}$ & - & - & $\mathrm{X}$ & - & - & - & $\mathrm{X}$ \\
\hline
\end{tabular}

$\mathrm{X}$ depicts when an animal was sighted. All individuals were identified in 1993 when effort was increased
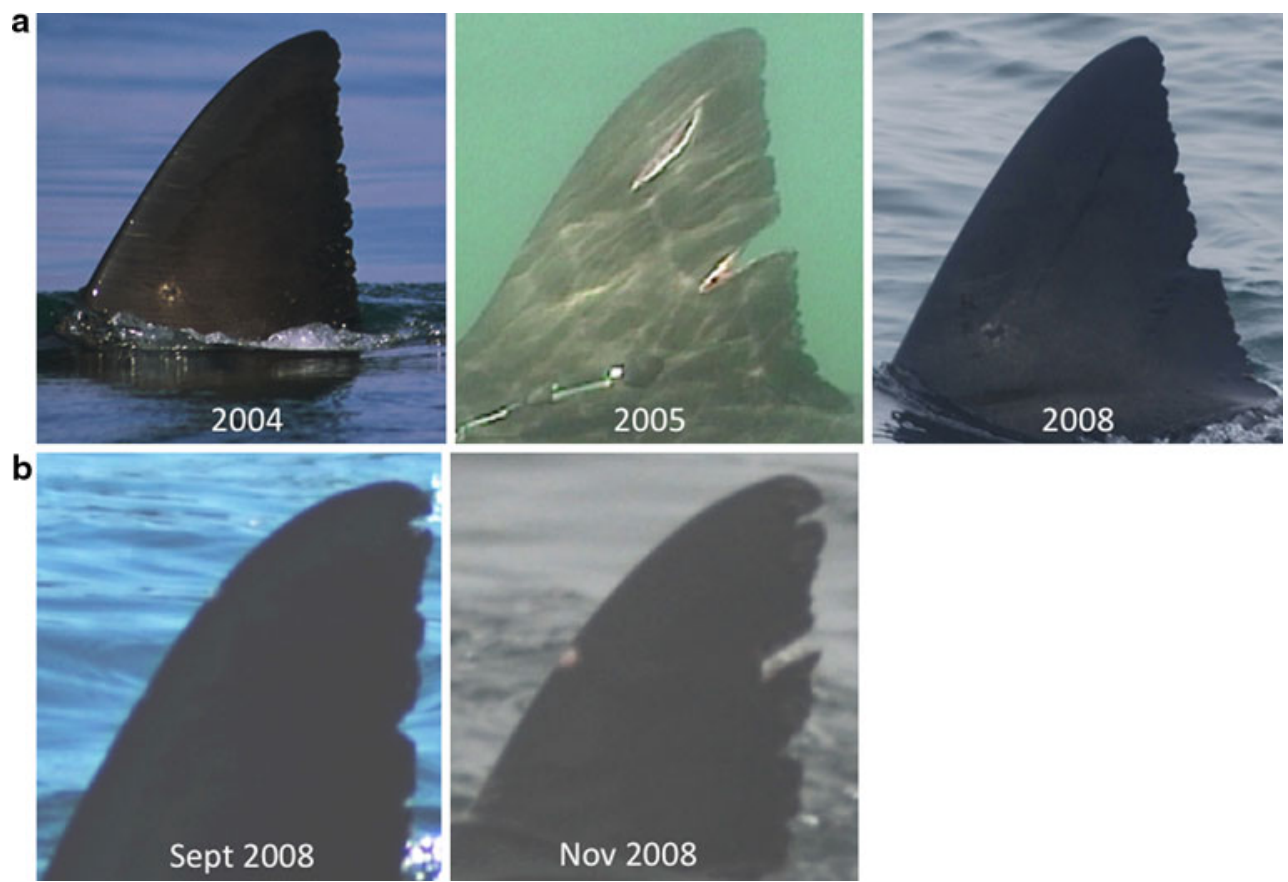

Fig. 3 Identification of fins after observations of fin damage. a A female shark photographed in 2004 with a complete fin, in 2005 with large lacerations on the fin, and in 2008 with scars from the damage,

the use of secondary characteristics and comparisons of first and last photographs of these five sharks, we found no evidence of changes in the size, shape, or arrangement of existing notches on these fins. We did, however, identify two sharks that incurred changes to their dorsal fins within the study period. These two sharks, a 4.9-m-TL female photographed each year from 2004 to 2008 (Fig. 3a) and a 4.3-m-TL male sighted November 07, 2008, and again 11 days later on November 18 (Fig. 3b), were shown to incur damage to their dorsal fins over the periods sighted. Though the trailing edge of the dorsal fin was damaged, creating a new notch, identifiable markings above and below this notch remained unchanged and sufficient for identification, illustrating how even relatively major fin trauma may results in the addition of a notch while leaving ample morphologic information for a positive identification. It is possible that the entire fin edge could be removed or altered due to major trauma preventing matching to but all other distinguishing markings intact. b A second shark showing new damage over a two-month period in 2008

previous sightings, but we saw no indication of this type of trauma during the 22 years of this study, which suggests this would be an extremely rare occurrence.

Dorsal fin identification also supports the long-term ( $\geq 15$ years) site fidelity of white sharks at coastal aggregation sites and provides the longest empirical documentation of white shark longevity to date, $>22$ years. Individual identification illustrated that animals returned to these sites consistently throughout the study period and potentially during their entire adult life span. Each animal was not necessarily seen every year, but unequal effort across both spatial and temporal scales most likely contributed greatly to such gaps in identification. Additionally, the prevalence of short-term resights ( $<5$ years) is also largely attributed to increased effort during the last 3 years of the study (Fig. 1).

This methodology, obtaining one photograph of the dorsal fin, requires far less effort than methods to document body pigmentation patterns and does not suffer from large 
rates of tag shedding or biofouling as traditional tagging methods do. Many of the white sharks in this study have been tagged with (on occasion multiple) pop-off archival tags, ultrasonic transmitters and/or floy tags, which have the potential to shed within a short time span $(<1$ year) (Jorgensen et al. 2010), precluding their use in long-term mark-recapture studies. In addition, further effort to automate the matching process will make the process more feasible with large datasets, allowing for the universal comparison of animals across different geographic regions regardless of diving effort or water clarity conditions.

Dorsal fin identification offers the foundation for markrecapture studies to quantify the population size and trends of white sharks. If possible, we suggest all available data be recorded (e.g., fin photographs and body pigments). However, white shark studies are often very difficult and costly. Therefore, we propose that dorsal fins, because of their ease in recording, illustrated longevity and potential for universal application, be prioritized as a method to document individual white sharks. This methodology cannot only be used to monitor the status of the white shark population in the northeast Pacific, but unlike other photo-identification methods, it can be more uniformly applied to archive white sharks worldwide, standardizing documentation of individuals across vast spatial and temporal scales.

Acknowledgments We thank J. Cornelius, M. Peterson, R. Elliot, P. Kanive, J. Barlow, K \& C Chapple, L. Lamas, and B Cornapple for assistance with fieldwork, laboratory work, data processing, and editing. We are grateful to S. McAfee, J. Fitzgerald, S. Neil, B. Becker, R Theiss, E. Homer, and crew of the R.S.V. Derek M. Bayliss for vessel and logistical assistance. This project was funded by PEMREM, NOAA-Seagrant, the Sloan, Moore and Packard Foundations as a part of the Tagging of Pacific Pelagics (TOPP) program of the Census of Marine Life. The Monterey Bay Aquarium Foundation, Pacific Coast Science and Learning Center, Patricia King and Bodega Marine Laboratory inter-campus travel grants also provided financial support. The project was conducted with permits from CDFG, MBNMS, GFNMS, NOAA, NPS and under University of California, Davis animal care protocol 15024 and Stanford University animal care protocol 10765.

Open Access This article is distributed under the terms of the Creative Commons Attribution Noncommercial License which permits any noncommercial use, distribution, and reproduction in any medium, provided the original author(s) and source are credited.

\section{References}

Anderson SD, Henderson RP, Pyle P, Ainley DG, Klimley AP (1996) White shark reactions to unbaited decoys. In: Klimley AP, Ainley
DG (eds) Great white sharks: the biology of Carcharodon carcharias. Academic, San Diego, pp 223-228

Bonfil R, Meyer M, Scholl MC, Johnson R, O'Brien S, Oosthuizen H, Swanson S, Kotze D, Paterson M (2005) Transoceanic migration, spatial dynamics, and population linkages of white sharks. Science 310:100. doi:10.1126/science. 1114898

Boustany A, Davis S, Pyle P, Anderson S, Le Boeuf B, Block B (2002) Satellite tagging-expanded niche for white sharks. Nature 415:35-36. doi:10.1038/415035b

Cailliet GM, Natanson LJ, Welden BA, Ebert DA (1985) Preliminary studies on the age and growth of the white shark, Carcharodon carcharias, using vertebral bands. Mem Calif Acad Sci 9:49-60

Chapple TK, Jorgensen SJ, Anderson SA, Kanive PE, Klimley AP, Botsford LW, Block BA (2011) A first estimate of white shark, Carcharodon carcharias, abundance off central California. Mar Biol (in press)

Cliff G, van der Elst RP, Govender A, Witthuhn TK, Bullen EM (1996) First estimates of mortality and population size of white sharks on the South African coast. In: Klimley AP, Ainley DG (eds) Great white sharks: the biology of Carcharodon carcharias. Academic Press, San Diego, pp 393-400

Domeier M, Nasby-Lucas N (2007) Annual re-sightings of photographically identified white sharks (Carcharodon carcharias) at an eastern Pacific aggregation site (Guadalupe Island, Mexico). Mar Biol 150:977-984. doi:10.1007/s00227-006-0380-7

Domeier M, Nasby-Lucas N (2008) Migration patterns of white sharks Carcharodon carcharias tagged at Guadalupe Island, Mexico, and identification of an eastern Pacific shared offshore foraging area. Mar Ecol-Prog Ser 370:221-237. doi:10.3354/meps07628

Gubili C, Johnson R, Gennari E, Oosthuizen W, Kotze D, Meyer M, Sims D, Jones C, Noble L (2009) Concordance of genetic and fin photo identification in the great white shark, Carcharodon carcharias, off Mossel Bay, South Africa. Mar Biol 156:2199-2207. doi:10.1007/s00227-009-1233-y

Jorgensen SJ, Reeb CA, Chapple TK, Anderson SD, Perle C, Van Sommeran SR, Fritz-Cope C, Brown AC, Klimley AP, Block BA (2010) Philopatry and migration of Pacific white sharks. P Roy Soc B-Biol Sci 277:679-688. doi:10.1098/rspb.2009.1155

Klimley AP, Anderson SD (1996) Residency patterns of white sharks at the south Farallon Islands, California. In: Klimley AP, Ainley DG (eds) Great white sharks: the biology of Carcharodon carcharias. Academic Press, San Diego, pp 365-374

Strong WR, Bruce BD, Nelson DR, Murphy RD (1996) Population dynamics of white sharks in Spencer Gulf, South Australia. In: Klimley AP, Ainley DG (eds) Great white sharks: the biology of Carcharodon carcharias. San Diego, Academic Press, pp 401-414

Weng KC, Boustany AM, Pyle P, Anderson SD, Brown A, Block B (2007) Migration and habitat of white sharks (Carcharodon carcharias) in the eastern Pacific Ocean. Mar Biol 152:877-894. doi:10.1007/s00227-007-0739-4 